\title{
A viagem entre o feitiço e a maldição
}

\author{
Mário Matos \\ Centro de Estudos Humanísticos, Instituto de Letras e Ciências Humanas, Universidade \\ do Minho
}

Resumo: Este contributo debruça-se sobre a multifacetada conceptualização da viagem na história cultural do Ocidente. Serão abordados diversos discursos que, ao longo dos tempos, oscilam entre visões céticas e restritivas, por um lado, e perspectivações deveras enaltecedoras da viagem. Analisando as visões do fenómeno da viagem sob o binómio feitiço/maldição, serão expostos os diferentes contextos e fatores históricos que foram determinando o valor da viagem que varia entre um grande poder de atração e sua restrição por sistemas religiosos e políticos fechados sobre si mesmos.

Palavras-chave: história cultural, viagem, turismo, média, proibição, feitiço, maldição

Abstract: This contribution focuses on the multifaceted conceptualization of travel in Western cultural history. Several discourses will be addressed that, over time, have oscillated between the sceptical and restrictive on the one hand, and the truly admiring perspectives of the journey on the other. A number of visions of the phenomenon of travel under the binomial spell/curse will be analysed. The different contexts and historical factors that determined the value of travel will be exposed, from its great power of attraction to its restriction by inward looking religious and political systems.

Keywords: cultural history, travel, journey, tourism, media, ban, spell, curse 


\section{Introdução}

A viagem, entendida quer como campo conceptual e semântico quer como prática e experiência sociocultural, ocupa inquestionavelmente um papel de destaque tanto na história como no presente da humanidade. No pluridimensional e multifacetado fenómeno da viagem condensam-se e refletem-se não só as mudanças ocorridas ao nível das visões e representações do mundo, das auto e heteroperceções sobre as quais assentam as construções de identidades e alteridades individuais e coletivas, como também as transformações tecnológicas que foram acontecendo ao longo dos tempos. Neste sentido, poder-se-á considerar o estudo das multiformes práticas e representações da viagem uma espécie de sismografia cultural que regista os principais traços indicadores das continuidades e descontinuidades do sinuoso processo civilizacional. Para além de sustentar hoje um dos mais poderosos ramos económicos a nível global sob a forma do turismo, a viagem constituiu ao longo da história um recorrente objeto de reflexão no pensamento ocidental e representa uma das mais persistentes metáforas nos mais diversos discursos e géneros literárias, o que reflete de uma forma inequívoca a sua importância capital relativamente a questões epistemológicas, estético-culturais e socioeconómicas.

Essa relevância manifesta-se numa multissecular tradição discursiva que concebe a viagem, modo geral, como um meio privilegiado para a experiência e aprendizagem da realidade exterior, ao mesmo tempo que possibilitará o autoconhecimento da figura do viajante proporcionando-lhe por conseguinte formação pessoal e cultural. No entanto, este entendimento tão abonatório do fenómeno da viagem é apenas uma face da medalha. Enquanto a visão enaltecedora da viagem remonta, no fundo, ao ideário pós-medieval do humanismo, sendo posteriormente reforçada pelos valores iluministas da liberdade, da tolerância intercultural e do cosmopolitismo que seriam potenciados nos séculos subsequentes, existe também um outro eixo discursivo em torno da viagem que não a concebe de forma tão apologética. Não obstante esta visão mais cética da viagem parecer estar à primeira vista relacionada com a massificação turística e a generalização da tele-experiência do longínquo proporcionada pelos novos meios de comunicação audiovisuais e digitais em tempos mais recentes, facto é que também esta perspetivação menos otimista se inscreve numa tradição discursiva que antecede a suposta “liquidação da viagem” (Virilio 2000: 38s) numa contemporaneidade caracterizada pela hipermobilidade tanto física como virtual que alegadamente transformaria a viagem propriamente dita numa inutilidade.

Como aqui se pretende demonstrar, a viagem nem sempre foi vista de forma tão unanimemente positiva como parece sugerir a sua conotação de certo modo mítica ou fantástica ao longo dos últimos três séculos da era moderna. Em termos sumários, poder-se-á dizer que a perceção do fenómeno da viagem oscila ao longo dos tempos entre o feitiço e a maldição. Para ilustrar essa ambivalência, serão aqui apresentados e analisados, em primeiro lugar, dois tipos de linhas discursivas que, 
embora por motivos diferentes, têm desde há mais de um século insistido no anúncio apocalíptico do fim das "verdadeiras" viagens. A segunda parte abordará, ainda que de forma muito sucinta, a longa história da proibição da viagem decretada por sistemas de pensamento religiosa ou politicamente fechados que temeram o poder de contágio ideológico inerente à mobilidade transcultural dos indivíduos. No final, verificar-se-á como o mítico desejo de viajar, ou seja, o feitiço da viagem foi sempre capaz de superar os muros e fronteiras com que os poderes autocratas tentaram em vão defender-se de uma suposta maldição da viagem.

I.

No prólogo a um volume editado em 2016, composto de dezanove relatos de viagens feitas entre 1994 e 2015 que já tinham sido previamente publicados avulso pela escritora e jornalista Sibylle Berg, cidadã de nacionalidade suíça nascida na extinta República Democrática Alemã, pode ler-se o seguinte:

Wie seltsam schnell und doch verzögert in der Wahrnehmung sich die Welt verändert. Hat. In den Synapsen stecken immer noch die Bilder von früher. Von reizenden Reisen. Da einem, ausser einer Darmgrippe, nichts passieren konnte. (Berg 2016: 5)

[Quão estranhamente rápido e contudo retardado na perceção se transforma o mundo. Se transformou. Nas sinapses encontram-se ainda as imagens de outrora. De viagens encantadoras. Uma vez que, para além de uma gripe intestinal, nada nos podia acontecer.]'

Se bem que esta constatação tenha sido feita num contexto anterior à atual pandemia global do novo coronavírus que veio temporariamente travar a hipermobilidade tão característica dos tempos contemporâneos, o espírito tanto melancólico como denunciatório que atravessa todo o livro de viagens de Berg com o título sintomático Wunderbare Jahre. Als wir noch die Welt bereisten [Anos maravilhosos. Quando ainda viajávamos pelo mundo] afigura-se como um pronúncio assertivo do fim (provisório) das viagens transfronteiriças numa era em que o mundo se terá tornado, pelas mais diversas razões, num lugar cada vez mais inóspito. Tendo experienciado, durante as suas inúmeras viagens aos mais diversas países e regiões do globo, populações assoladas por repressão, fome, guerras, atentados, catástrofes ecológicas e epidemias, esta viajante-narradora conclui, só aparentemente de forma prosaica, num tom que oscila entre a ironia e a nostalgia:

Es muss ja auch keiner mehr verreisen. Es gibt auf 3Sat und Arte täglich diese wunderbaren Sendungen, in der die Welt in Ordnung ist. Einfache, herzensgute Menschen machen Handwerk, sie sind gastfreundlich, und Attentate finden nicht statt. Entführungen 
gibt es nicht. Den Ekel vor dem weissen Touristen sehen wir kaum. Und wer nicht fernsehen will, kann Geschichten lesen, von früher. Als wir noch die Welt bereisten. (Idem: 6)

[Mas também já nem sequer é preciso viajar. Nos canais de televisão por cabo 3Sat e Arte há diariamente aqueles programas maravilhosos em que o mundo está em ordem. Pessoas simples e bondosas fazem artesanato, são hospitaleiras, e não acontecem atentados. Não há sequestros. 0 nojo que têm do turista branco mal se vê. E quem não quiser ver televisão pode ler histórias, de outrora. Quando ainda viajávamos pelo mundo.]

Apesar desta espécie de canto de cisne se ter intensificado sobretudo durante as últimas décadas, numa desordem global marcada por males de índole diversa à escala planetária, na verdade, o discurso premonitório do fim das viagens remonta já a uma longa tradição que curiosamente antecede não só massificação da viagem por via do turismo, como veremos mais à frente, mas também a mediação de visões de qualquer recanto do globo proporcionados quer pelos meios audiovisuais analógicos, como o cinema e a televisão, quer pelos digitais via internet. A literatura, sobretudo a do século XX, é bastante fértil em alegações sobre o desaparecimento progressivo da viagem física, desaparecimento esse pretensamente induzido pelos novos meios telemáticos que nos trazem o mundo pelas salas-de-estar adentro.

A título de exemplo, recue-se aqui a 1957, ano de publicação do romance diarístico Homo faber. Ein Bericht de Max Frisch, também este um autor suíço de língua alemã. A dada altura deste "relato", assim o subtítulo do romance muito complexo em que se entrecruzam múltiplos tempos e lugares, ${ }^{2}$ o seu protagonista e narrador na primeira pessoa Walter Faber, um verdadeiro globetrotter em constante mobilidade por razões tanto profissionais como pessoais, representando assim o novo tipo de cidadão cosmopolita dos tempos (pós-)modernos que passa parte significativa da sua vida em aviões, navios e comboios, recorda-se ironicamente da profecia de um seu antigo professor dos tempos da universidade que, nos anos de 1930, se dirigira aos seus estudantes de engenharia mecânica com a seguinte afirmação:

Reisen, meine Herren, ist mittelalterlich, wir haben heute schon Mittel der Kommunikation, geschweige denn morgen und übermorgen, Mittel der Kommunikation, die uns die Welt ins Haus liefern, es ist ein Atavismus, von einem Ort zum andern zu fahren. Sie lachen, meine Herren, aber es ist so, Reisen ist ein Atavismus, es wird kommen der Tag, da es überhaupt keinen Verkehr mehr gibt, und nur noch die Hochzeitspaare werden mit einer Droschke durch die Welt fahren, sonst kein Mensch. Sie lachen, meine Herren, aber Sie werden es noch erleben! (Frisch 1977: 103s.)

[Viajar, meus senhores, é medievalesco; hoje, já temos meios de comunicação, que fará amanhã e depois de amanhã, que nos trazem o mundo pelas casas adentro; ir de um 
lado para outro é, pois, um atavismo. Vocês riem-se, meus senhores, mas é mesmo assim, viajar é um atavismo; virá o dia em que já não haverá qualquer tipo de trânsito e em que apenas os recém-casados se passearão [durante as núpcias] de coche pelo mundo e mais ninguém. Vocês riem-se, meus senhores, mas ainda o irão vivenciar.]

Um outro exemplo literário, entre muitos outros possíveis, do profético anúncio do fim das viagens alegadamente causado pelos novos meios tecnológicos é a seguinte passagem do famoso conto "O Aleph" de Jorge Luís Borges. Nas palavras de um dos seus personagens, um poeta que, devido à evolução da tecnologia, considera possível executar a megalómana tarefa de "versificar toda a redondeza do planeta" (Borges 1998: 641),

(...) o homem moderno (...) está provido de telefones, de telégrafo, de fonógrafos, de aparelhos de radiotelefonia, de cinematógrafos, de lanternas mágicas (...). (...) [P]ara um homem assim dotado, o acto de viajar [é] inútil; o nosso século XX (transformou) a fábula de Maomé e da montanha; as montanhas, agora, (convergem) sobre o moderno Maomé. (idem: 639)

Desde a primeira publicação desta narrativa, em 1949, surgiram outros aparelhos telemáticos, como a televisão e a internet, que entretanto se impuseram a nível global e vieram transformar radicalmente o nosso acesso ao mundo longínquo. Por isso, não surpreende que o impacto destes poderosos dispositivos que alteram as noções e perceções espaciais e temporais tenham suscitado diversos tipos de reflexões e discursos de ordem ora mais ora menos epistemológica que alegam uma progressiva substituição da viagem física pelo ato de um deslocamento virtual. Em relação ao impacto da evolução tecnológica desde a revolução dos transportes à dos meios telemáticos que durante as últimas décadas contribuíram para uma notória compressão do tempo e do espaço, o ensaísta francês Paul Virilio, por exemplo, afirmava, em 1995, num volume originalmente publicado sob o título La Vitesse de Libération:

Ao passo que o deslocamento físico de um ponto a outro supunha, outrora, uma partida, uma viagem e uma chegada, a revolução dos transportes efectuara já, no século passado, uma liquidação progressiva da demora e da própria natureza da viagem (...). Actualmente, com a revolução das transmissões instantâneas, assistimos às primícias de uma «chegada generalizada» onde tudo chega sem que seja necessário partir; a liquidação da viagem (quer dizer, do intervalo de espaço e de tempo) do século XIX, volve-se neste final o século XX em eliminação da partida, perdendo assim o trajecto os componentes sucessivos que o constituíam, em benefício, unicamente, da chegada. (Virilio 2000: 38s) ${ }^{3}$

Nas suas abordagens críticas do fenómeno da velocidade e aceleração que culminariam na instantaneidade da comunicação e representação nos mais recentes 
meios digitais, área de estudo que o próprio Virilio denominou de dromologia, são invocados diversos aspetos relacionados com o tema da viagem bastante relevantes para o presente ensaio, designadamente a sua conceção da mobilidade numa época contemporânea marcada por uma "verdadeira cultura do paradoxo, onde tudo chega sem que seja necessário não apenas deslocar-se fisicamente, mas igualmente partir" (idem: 42). Há vinte cinco anos, portanto numa altura em que a internet, incluindo a acessibilidade móvel por via dos smartphones, ainda não tinha atingido as suas potencialidades de hoje, Virilio apontava para um cenário que a atual paragem da mobilidade física causada pela pandemia da covid-ı está a pôr literalmente à prova:

[A]li onde a motorização dos transportes e da informação tinha provocado uma mobilização geral de populações arrastadas no êxodo do trabalho, e depois dos lazeres, os meios de transmissão instantânea provocam, inversamente, uma inércia crescente, a televisão e sobretudo a tele-acção já não necessitam da mobilidade das pessoas, mas apenas da sua mobilidade no mesmo lugar. (idem: 43)

Na mesma senda, num volume ensaístico de 1998 intitulado Von Raum zu Raum. Versuch über das Reisen [De um espaço para o outro. Ensaio sobre a viagem], o autor suíço Aurel Schmidt, referindo-se igualmente à progressiva substituição do espaço físico pelo ciberespaço, proclamava mesmo o aniquilamento de qualquer forma de mobilidade física: "Die elektronische Fiktion hat jede physische Ortsveränderung überflüssig gemacht und die analoge Reise ausgeschaltet.” (Schmidt 1998: 44). [A ficção eletrónica tornou supérflua qualquer mudança de local física e liquidou a viagem analógica.]

2.

Se a evolução tecnológica, designadamente a dos meios telemáticos tanto analógicos como digitais, fornece portanto a base argumentativa de um discurso que evoca o fim das viagens físicas num mundo pós-material da simultaneidade, há também todo um outro eixo discursivo que alega não a substituição do ato de deslocação em si, mas sim a morte das "verdadeiras viagens" na era do turismo de massas.

Em relação a este prenúncio do fim das viagens "autênticas", alegadamente causado por uma indústria que fornece cada vez mais comodidades a cada vez mais viajantes tendendo assim a uniformizar a experiência da viagem, é curioso verificar-se que esse discurso nostálgico não acompanha apenas a evolução do turismo desde a sua institucionalização por via das primeiras agências de viagens, como a de Thomas Cook na Grã-Bretanha ou mesmo a portuguesa Abreu, a partir de meados do século XIX. Muito antes de se poder falar de uma democratização ou massificação propriamente ditas da viagem de lazer, o que em boa verdade nas sociedades industrializadas viria a acontecer apenas no pós- Segunda Guerra Mundial, é possível detetar toda uma 
longa e persistente tradição discursiva de "ferocious denigration of tourists" (Culler 198I: 129), tradição essa que remonta pelo menos até finais do século XVIII, se intensificou durante o século XIX, prevaleceu no século passado e resistiu inclusive pelo terceiro milénio adentro. ${ }^{4}$

Não é difícil elencar, a título paradigmático, vários exemplos dessa história menos conhecida do metadiscurso crítico em torno da viagem turística, começando na chamada época dourada da Bildungsreise (viagem cultural), ou seja, na segunda metade do século XVIII, altura em que se assistiu à primeira fase de uma gradual democratização da mobilidade transcultural fomentada pelos ideais iluministas de uma burguesia cosmopolita (Weltbürgertum), para quem a viagem significava um meio por excelência quer para a formação pessoal, quer para a afirmação coletiva de uma classe (pretensamente culta) em clara ascensão social e política. Ao penetrar num espaço anteriormente reservado à aristocracia sob a forma da Grand Tour, essa nova classe de cosmopolitas burgueses, na sua maioria oriunda da Inglaterra, da França e da Alemanha, desencadearia o que, para a época, se pode considerar um boom da viagem de formação cultural, isto é, da mobilidade transfronteiriça em lazer. Esse novo frenesim resultaria naturalmente num número considerável de relatos de viagens, um género literário que rapidamente invadiria o emergente mercado livreiro e conquistaria o gosto dos leitores. É neste contexto histórico-cultural que se inserem os seguintes reparos do estudioso alemão Archenholz (1784: 151), numa carta de leitor ao editor da influente revista cultural Teutscher Merkur publicada em 1784, em que se critica severamente a "epidemia da viagem" e os respetivos relatos alegadamente desprovidos de qualquer qualidade ao nível do conteúdo e da forma:

In keinem Zeitalter der Welt wurde so viel gereist, als in dem unsrigen, wo das Reisen zu einer Art Epidemie geworden ist. (...) Es ist wohl kein Wunder, dass bey so häuffigen Reisen in unsern bücherreichen Zeiten der Reisebeschreibungen so viele verfertigt werden.

[Em nenhuma outra época tanto se viajou como nos nossos tempos, nos quais viajar se tornou uma espécie de epidemia. (...) Não é portanto um milagre que, com tantas viagens, nos nossos tempos ricos em livros se redijam tantos relatos de viagens.]

Escusado será dizer que o vírus que teria desencadeado essa alegada "epidemia da viagem” não operava de um modo socialmente transversal, uma vez que no último quartel do século XVIII viajar sem outro fim senão o da (auto-)formação cultural e/ ou do mero prazer ainda era, sem margens para dúvidas, um privilégio da velha aristocracia e de uma nova burguesia em ascensão. Dever-se-á portanto considerar que a denúncia de Archenholz - ou melhor, o seu ataque verbalmente bastante violento não se coibindo de recorrer a palavras de cargas conotativas extremamente negativas, tais como “nojo” (idem: 152), a ignorância da "plebe dos leitores” (ibidem) e o 
“descaramento" dos “pseudo-estudiosos” (ibidem) - representa uma desproporcional hiper-reação a uma suposta vaga da viagem e de livros de viagens que, na realidade, diziam apenas respeito a uma elite social. Dito por outras palavras, esta crítica a uma crescente mobilidade transfronteiriça e, consequentemente, ao inevitável aumento de publicações sobre a viagem constitui um exemplo deveras ilustrativo da longevidade de uma certa tradição discursiva que, ainda muita antes de se ter verificado uma verdadeira democratização social da viagem, tem insistido, desde há pelo menos dois séculos, em denegrir a imagem do viajante comum como L'ldiot du Voyage (Urbain 2002). Como se poderá ver de seguida, a história da literatura é fértil nesse género de insinuações insultuosas à figura do “viajante inculto". Atente-se brevemente em alguns exemplos desse longo cadastro de defeitos atribuídos no meio literário à figura do “viajante vulgar", isto é, do turista.

Mais ou menos dez anos depois da referida denúncia de Archenholz, também o famoso filósofo e escritor alemão Johann Gottfried Herder fazia referência a essa nova espécie de "epidemia da viagem" tão característica do lluminismo tardio. Numa das suas célebres Briefe zur Beförderung der Humanität (Cartas para a Elevação e o Progresso da Humanidade), originalmente editadas em dez volumes entre 1793 e 1797, reportando-se ao aumento exponencial de edições de relatos de viagens na segunda metade do século XVIII constata a "fúria filosófica" com que os ociosos europeus palmilhavam o mundo: “(...) alles läuft, was in Europa nichts zu tun hat, mit einer Art philosophischer Wut über die Erde.” (Herder 197ı: Bd. 2, 218) [Tudo o que na Europa nada tem para fazer corre pelo mundo com uma espécie de fúria filosófica.]

Dando-se um salto de duas décadas para a frente, nomeadamente para o ano de 1817, depara-se com a seguinte impressão de viagem de Lord Byron relativamente a Roma, a qual descreveu como um local "pestilential with English, - a parcel of staring boobies, who go about gaping and wishing to be at once cheap and magnificient", turistas esses que, além de "inundarem” e “empestarem” as históricas capitais da arte, também "envenenavam toda a cena” natural oferecida pela bela paisagem montanhosa da Suíça: “(...) in Switzerland (...) the most distant glimpse or aspect of [tourists] poisened the whole scene." (Apud Buzard 1998: 84).

Para se prosseguir com mais um exemplo do discurso antiturístico numa época anterior à massificação propriamente dita da viagem, em I826, num dos seus vários relatos das diversas viagens empreendidas a Itália, o romancista francês Stendhal, que alguns anos mais tarde se auto-denominaria como um dos primeiros escritores de "turista" dando a um dos seus textos (semi-)autobiográficos o título de Mémoires d'un touriste (1838), sente-se incomodado com o facto de encontrar as avenidas principais de Florença “encombrées de six cents Russes ou Anglais”, número aparentemente tão significativo que o leva a afirmar que "Florence n'est qu'un musée plein d'étrangers (...)." (Stendhal 1973: 490).

Na mesma linha de tantos outros famosos escritores-viajantes dos séculos XVIII 
e XIX, também Johann Wolfgang Goethe, que se iria transformar a partir da publicação da sua Viagem a Itália no modelo sublime de Bildungsreise(nder), ou seja, da «viagem de formação burguesa» e do «viajante culto», não deixou de lançar as suas farpas em relação ao aumento significativo de turistas britânicos, então claramente os “campeões da viagem”, nas principais rotas europeias. No seu famoso drama épico Fausto, cuja primeira parte foi pela primeira vez publicada em 1808, o contra-protagonista Mefistófeles faz, junto a uma pitoresca paisagem de ruínas situada na mítica serra do Harz alemão, o seguinte reparo:

Sind Briten hier? Sie reisen sonst so viel,

Schlachtfeldern nachzuspüren, Wasserfällen,

Gestürzte Mauern, klassisch dumpfen Stellen;

Das wäre hier für sie ein würdig Ziel.

[Há aqui britânicos? É que eles tanto costumam viajar

Para rastrearem campos de batalhas, quedas de água,

Muros caídos, sítios clássicos e sombrios;

Isto para eles seria um digno destino.]

Já na viragem para o século XX, designadamente em 1897, o romancista e dramaturgo alemão Gerhart Hauptmann refere-se às “massas inertes” da classe média que anualmente atravessam os Alpes rumo à Itália para ofuscar o esplendor artístico do tradicional e emblemático país da alta cultura:

Da strömen die Leute nach Italien, jeder Barbier und Schlächter tut es: Die ganze träge Masse des deutschen Philistertums walzt sich über die Berge, jahraus jahrein, und als dieselbe träge Masse wieder zurück. Nichts kann der Philister lernen. Er drückt und lagert wie Schlamm über der Kunst der Zeit. (Apud Hennig 1997: 14)

[As pessoas afluem em grande número a Itália, qualquer barbeiro e carniceiro o faz: toda a massa inerte dos filisteus alemães rola sobre as montanhas, ano após ano, e regressa como a mesma massa inerte que partiu. 0 filisteu nada é capaz de apreender. Ele pesa sobre a arte e cobre-a como lama.]

Como é fácil de intuir a partir destes poucos exemplos, a crítica ao turismo, paradoxalmente, antecede o próprio fenómeno do turismo moderno cuja dimensão verdadeiramente industrial só se iria denotar com os diversos surtos económicos ocorridos desde meados do século $\mathrm{XX}$, porventura a ritmos distintos entre as sociedades industrializadas, de onde partem os turistas, e aquelas em via de desenvolvimento que os acolhem. Num interessante estudo de 1993 dedicado ao tratamento desse 
tema na literatura (maioritariamente britânica) entre 1800 e 1918, James Buzard (1993) corrobora esta tese, ao elaborar e analisar uma vasta lista de comentários pejorativos, em parte mesmo insultuosos, proferidos por "distintos" escritores autoestilizados como "verdadeiros" viajantes que já no século XIX repudiam o homo turisticus e do qual, por isso, se tentam a todo custo diferenciar social e culturalmente. Este tipo de discurso diferenciador insiste falaciosamente numa rígida e clara linha de demarcação entre a figura do viajante, sublimemente encenada pelo escritor que vagueia pelo mundo de sentimentos e sentidos bem apurados, e, do outro lado, a caricatura do turista, que não só é frequentemente etiquetado de "superficial”, "insensível” e “torpe”, como é repetidamente evocado, de modo ainda mais ofensivo, com recurso a uma imagética animalesca que o representa, por exemplo, como "cordeiro" ou "inseto" que apenas se sabe mover estúpida e ordeiramente em rebanhos ou manadas. A seguinte crítica devastadora ao "turismo ocidental" como "um dos grandes movimentos niilistas, uma das grandes epidemias" cujos efeitos maléficos poderiam ser comparados aos "males vindos do Leste” (i.e., o Comunismo), crítica essa proferida, num relato de viagens publicado em 1950, pelo escritor alemão Gerhard Nebel, reflete - pela negativa - o grande empenho de muitos "verdadeiros viajantes” na construção literária do turista como "un «anti-mythe», (...) le doublet maudit du mythe du voyageur.” (Moura 2000: 270).

Der abendländische Tourismus ist eine der grossen nihilistischen Bewegungen, eine der grossen westlichen Seuchen, die an bösartiger Wirksamkeit kaum hinter den Epidemien der Mitte und des Ostens zurückbleiben (...). Die Schwärme dieser Riesenbakterien, Reisende genannt, überziehen die verschiedensten Substanzen mit dem gleichförmig schillernden Thomas-Cook-Schleim (...). [Es] bricht die europäische Krankheit in einer Kette von Eiterbeulen aus. Ein Land, das touristisch erschlossen wurde, verbirgt sich metaphysisch - es bietet eine Kulisse, aber nicht mehr seine dämonischen Kräfte dar. (Nebel 1950: 25)

[O turismo ocidental é um dos grandes movimentos niilistas, uma das grandes epidemias ocidentais, que, em termos de eficácia maligna, pouco ficam atrás das epidemias do médio e extremo Oriente ( ...). Os enxames dessas bactérias gigantes, chamadas viajantes, cobrem as mais diversas substâncias com o muco viscoso e uniformemente reluzente de Thomas Cook (...) A doença europeia irrompe com abcessos e pústulas a rebentarem em cadeia. Um país que tenha sido explorado para fins turísticos esconde-se metafisicamente - oferece um cenário, mas já não os seus poderes demoníacos.]

Face à sua extrema radicalidade, o discurso fascistóide de Nebel, que se manifesta sob a forma de uma impressionante acumulação de lexemas e metáforas decadentistas, tais como "bactérias gigantes”, “pústulas” ou “abcessos”, não pode ser 
considerado representativo da tradição crítica aqui exposta. A esmagadora maioria dessas críticas expressas pela elite dos escritores-viajantes veste-se, evidentemente, de roupagens mais elegantes, lançando as suas farpas venenosos, conforme já pudemos constatar, de modos mais subtis, muitas vezes eivadas de humor. 0 breve texto “Why not stay at home?”, com que Aldous Huxley abre a sua compilação de 1925 Along the Road. Notes and Essays of a Tourist ( $\left.{ }^{2} 1948\right)$, constitui um desses casos exemplares da elegância retórica, do tom irónico e satírico com que muitos "poetas da viagem "se tentam avidamente auto-diferenciar da "gloomy-looking tribe" (3) dos “inexperienced tourists” (5), esses “poor slaves” (9) que durante as suas excursões "desperately do their best to make external reality square with fable", "hanker[ing] after myhtology”, cegueira ou ingenuidade essas que alegadamente contrastam com o "genuine traveller [who] is so much interested in real things that he does not find it necessary to believe in fables." (10)

3.

Perante a crescente tomada de consciência da gigantesca pegada ecológica deixada pelo turismo, nomeadamente aquele de longa distância que envolve deslocamentos aéreos ou os cruzeiros sobremaneira poluentes dos mares, não surpreende que nos últimos anos se tenha também assistido a um discurso cada vez mais cético em relação ao turismo de massas. No entanto, e ainda que se trata de uma afirmação não sustentada pelas devidas análises, suspeito que essa crítica tende mais a manifestar-se enquanto discurso sociológico e/ou político com uma presença mais ou menos forte nos meios de comunicação e na opinião pública, e não tanto a de assumir a forma dum discurso literário expresso pelos próprios viajantes-narradores à semelhança do que se pôde verificar nos referidos exemplos tirados dos séculos XIX e XX. O discurso em torno da viagem será cada vez menos linear e unívoco, visto que o tom modo geral apologético relacionado com os seus benefícios, como a auto e hétero-formação, a fomentação da tolerância transcultural e a alavancagem das economias locais, que terá perdurado durante muito tempo, hoje terá obrigatoriamente de ombrear com uma visão a que muito dificilmente se poderá subtrair que denuncia os malefícios cientificamente provados da viagem sob a forma de turismo de massas. Perante esta ambivalência, esta oscilação entre as dimensões e figurações do bem e do mal da viagem, entre o seu feitiço e sua maldição, só podemos esperar que o tema da viagem não seja novamente instrumentalizado por ideologias, regimes e pensamentos políticos fechados, como tantas vezes foi acontecendo ao longo da história.

Para concluir este ensaio dedicado aos múltiplos meta-discursos da viagem, resta ainda expor, evidentemente de forma muito sucinta, alguns episódios de uma longa história da proibição da viagem que foi sendo temporariamente esquecida devido ao optimismo e à euforia que foi prevalecendo na apreciação do fenómeno da viagem. 
A viagem é, sem sombra de dúvidas, uma das figuras de pensamento e das metáforas mais presentes e marcantes na memória cultural do Ocidente. Desde as epopeias clássicas da antiguidade grega e romana, emblematicamente representadas pelas odisseias de Homero e Virgílio, passando por Cervantes e Camões, em cuja obra a viagem desempenha um papel fulcral, passando ainda pelas Utopias renascentistas de Morus, Campanella e Bacon, pelo Robinson Crusoe de Defoe e pela a famosa Viagem a Itália de Goethe, pelos romances de aventura e viagens de Melville e Conrad do século XIX, até aos autores do século XX, como, por exemplo, as obras de Joyce, Proust, Céline ou mesmo de Fernando Pessoa, mesmo sem sequer se levar aqui em consideração a literatura de viagens propriamente dita, verifica-se que o tema da viagem se estende como uma espécie de fio condutor pela história do cânone literário ocidental. No entanto, esse fio atravessa a história das ideias não de um modo linear, mas sinuoso, revestindo-se o conceito da viagem de um significado de pendor ora mais positivo, ora mais negativo.

Se remontarmos ao chamado «livro dos livros» da civilização judaico-cristã, ou seja, à Bíblia, verificaremos que a viagem tem aí de um modo geral uma conotação muito negativa. O castigo capital para Adão e Eva pelo cometer do pecado original é precisamente constituído pela expulsão do Paraíso. Desde então, a humanidade estaria eternamente condenada à viagem errática em busca da redenção, que seria o reencontrar da harmonia bucólica do Jardim de Éden anterior ao pecado.

Ainda no Velho Testamento, há a destacar pelo menos mais um episódio em que a viagem é concebida de modo negativo, como uma condenação à mobilidade forçada, a saber, as quatro décadas de fuga e errância pelo deserto por parte do povo liderado por Moisés, episódio este que se encontra na base da bimilenar figura mítica do «Judeu errante», um mito que encontrará ao longo dos tempos as mais diversas configurações em muitas obras da literatura ocidental.

Um outro protótipo do pensar-se e narrar-se a viagem costuma ser considerada a Odisseia de Homero que conta as aventuras e deambulações do mítico Ulisses. Se bem que este seja frequentemente descrito como o arquétipo por excelência da figura do viajante, na verdade Ulisses não viaja por vontade própria, pois, ele não empreende a viagem nem por sede de conhecimento, com o intuito de alargar os seus horizontes, nem tampouco como meio de redefinir a sua identidade por via do contacto com o Outro. O motivo da sua viagem é cumprir uma missão e voltar são e salvo a Ítaca. Ulisses não busca o contacto com a alteridade; pelo contrário, a sua viagem de regresso caracteriza-se precisamente pela sua obstinação de não se deixar cativar e contaminar pelo Outro e, muito menos, de nele se diluir, por mais maraviIhoso e sedutor que este se lhe possa apresentar. Ulisses não é portanto um viajante no sentido moderno de transgressor voluntário dos limites e das referências do seu quadro cultural. A dimensão heróica de Ulisses consiste na sua capacidade de se tornar imune a possíveis influências de outras culturas. Portanto, na Odisseia, a viagem 
é representada como uma prova de resistência, do amor e apego de Ulisses pela sua própria cultura de origem, não havendo espaço para um diálogo intercultural.

E girando de novo a roda do tempo, verifica-se que, também na Idade Média, a viagem é, de um modo geral, encarada como um mal necessário. A peregrinação cristã aos lugares santos não é um périplo de prazer e curiosidade, mas uma caminhada de sacrifício para a obtenção do perdão. Excepcionando os aristocratas, os comerciantes e os estudiosos escolásticos que viajavam de biblioteca em biblioteca, de convento em convento, os restantes viajantes que povoavam as vias da Europa medieval eram considerados vagabundos, desterrados sem posses, sendo por isso, pelo menos de acordo com a moral oficial da época, vistos como indesejados. Em boa verdade, esses ditos vagabundos eram os verdadeiros animadores das povoações por onde passavam, trazendo, como viajados que eram, notícias e novidades de regiões cujo acesso era vedado à generalidade da população pelas leis sedentárias do feudalismo que apelavam ao stabilitas loci, à imobilidade e estagnação.

O espírito humanista da Renascença significou um salto verdadeiramente paradigmático no que diz respeito à conceção da viagem. A substituição de uma visão teocêntrica do mundo por uma perspectiva, ao mesmo tempo, heliocêntrica e antropocêntrica, implicava necessariamente uma enorme valorização da experiência empírica, da observação de novas regiões, novas realidades naturais e novos povos com seus respetivos hábitos culturais. A viagem passa assim a ser considerada o meio por excelência para a obtenção de saberes e conhecimentos do mundo. Este enfático elogio da viagem como sinónimo de uma incessante busca cognitiva pela verdade, que já não se legitimaria por uma lógica teológica, mas agora se explicaria pela observação e experiência empírica do Outro, doravante trespassaria toda uma série de "grandes narrativas”, incluindo várias "utopias de Estado".

Conforme constata Kornelius Schütze (1995: 13) num interessante volume ensaístico significativamente intitulado de Gefährliche Geographie (Geografia Perigosa), no "horizonte da utopia”, a viagem não só constitui um tópico imprescindível ou mes. mo constitutivo, como é, modo geral, concebida como um "sinónimo de liberdade". Esta tradicional associação direta entre utopia, viagem e liberdade tem, assim, impedido que se tome consciência de que a maioria das narrativas utópicas assenta na restrição proibitiva da mobilidade física dos cidadãos desses "estados perfeitos". Ao longo da história muitos foram pois os "gestores de utopias" que "restringiram fortemente a viagem ou a proibiram mesmo por completo" com o manifesto propósito de precaver uma infiltração de "novidades ameaçadoras" à estabilidade do sistema e, por conseguinte, à pressuposta felicidade dos habitantes. De facto, Schütze dá diversos exemplos de uma longa história de proibição da viagem, desde a colónia agrária na ilha de Creta projectada nas Leis de Platão, em que só aos sábios anciãos seria permitido viajar na função de “observadores”, passando pela referência à obrigatoriedade de se possuir uma autorização oficial emitida pelo Estado sem o qual os 
habitantes da ilha Utopia de Thomas Morus não podiam deslocar-se além-fronteiras, pela Nova Atlântida de Francis Bacon, onde havia uma "academia" que regulava com rigor a entrada e saída de viajantes estrangeiros e autóctones, até ao modelo economicamente autarca do Geschlossener Handelsstaat (I800) [Estado de comércio fechado] esboçado pelo filósofo nacionalista alemão J. G. Fichte, cujo “Estado da Razão” limitaria o acesso à viagem transfronteiriça apenas aos “estudiosos e artistas sublimes”. Há portanto numerosos casos que ilustram uma tradição restritiva em relação à mobilidade que caracteriza esse género de narrativas utópicas.

Não obstante o paradoxo de nas mais famosos utopias de estado clássicas, renascentistas e iluministas se verificarem restrições à viagem, facto é que, mais tardar desde o século XVI, a viagem passa a simbolizar por excelência o ideal filantropo e cosmopolita da liberdade que tem persistido quase incólume até aos nossos tempos.

No entanto, mesmo no século XX, em plena era da mobilidade e turismo de massas, houve tentativas de isolar sociedades e estados inteiros do acesso às viagens. Os paralelismos entre as clássicas construções ficcionais e/ou filosóficas de estados virtuais e o funcionamento concreto em sistemas político-ideológicos em que vigoraram o chamado "Nacional-Socialismo", na Alemanha entre 1933 e 1945, ou mesmo o "Socialismo Real” (realexistierender Sozialismus), na República Democrática Alemã de 1949 até 1989, são por de mais evidentes. Como tentei demonstrar detalhadamente noutros lugares (Matos 20IOa e 20IOb), para esses regimes ditatoriais a viagem foi sempre uma assunto da maior relevância e importância política sendo fortemente controlada e instrumentalizada pelo poder de estado, para assegurar, por um lado, a paz social possibilitando um turismo fortemente controlado sob a alçado do estado, e por outro, para limitar os destinos turísticos a países com regimes semelhantes onde não era suposto não haver influências ideológicas indesejáveis. Neste sentido, pode-se considerar que houve vários subtipos de turismo claramente politizados, sendo possível falar-se tanto de um "turismo pan-fascista" entre 1933 e 1945, como de um “turismo pan-socialista” entre 1949 e 1990.

Depois do colapso das últimas grandes utopias sociais e políticas, que poderemos situar há precisamente 30 anos com a chamada queda do Muro de Berlim e um pouco depois com a implosão da União Soviética, a crença na viagem como libertação - mais que não seja, temporária - tanto das algemas de um regime político repressivo como de uma civilização (pós-)industrial extremamente competitiva e conflituosa, parece ser o último reduto em que o ser humano oriundo das sociedades industrializadas procura o efémero paraíso, paraíso esse que é prometido e vendido pelas agências de viagens - porventura, a preços inacessíveis à parte substancialmente maior da população mundial e que, ainda por cima, neste momento se encontra suspenso por razões sanitárias.

A história recente demonstrou definitivamente que o i-mobilismo, o provincianismo decretado e imposto pelo Estado, nunca foi capaz de conferir genericamente 
uma identidade estável e feliz aos cidadãos que habitavam por exemplo os países supostamente socialistas do antigo Bloco de Leste. Resta saber se o frenesim da viagem, a "mobilidade total” a que globalização nos parece obrigar ou mesmo condenar, será capaz de nos transformar em cidadãos do mundo mais felizes e, por conseguinte, mais tolerantes. A recente paragem abrupta devido à atual pandemia global, pandemia esta que foi sobremaneira potenciada pela enorme intensidade da nossa mobilidade física, veio inesperadamente obrigar-nos a refletir de novo, agora sob novos pressupostos que vão para além da questão ecológica, acerca desta complexa temática da(s) mobilidade(s), incluindo tantos as viagens físicas como as telemáticas.

Terminada a era das "grandes narrativas" teleológicas, sejam elas religiosas ou políticas, que durante séculos nos prometeram ora o regresso ao "Paraíso celeste", ora uma felicidade plena sobre a terra, terra esta que em termos ecológicos se está a tornar inabitável, parece que estamos condenados a uma viagem interminável em busca de algo que já não sabemos bem o que é. Estaremos condenados a um nomadismo eterno sem destino concreto, a não ser o de viver a ilusão de alguns breves e efémeros momentos, fragmentos apenas, de uma bucólica felicidade encenada no gigantesco mundo de faz-de-conta que a indústria turística nos proporciona? Será esse o verdadeiro móbil que até há bem pouco tempo levava anualmente várias centenas de milhões de indivíduos a fazerem as malas e a se submeterem de livre vontade às peripécias - quase sempre caras, por vezes extremamente cansativas e mesmo perigosas - da viagem?

Apesar das transmissões televisivas em direto de qualquer acontecimento que esteja a decorrer em qualquer canto do mundo e da possibilidade de podermos aceder visualmente a (quase) qualquer lugar de modo instantâneo por via de webcams instaladas um pouco por todo o globo, apesar dessas “maravilhas” tecnológicas que nos possibilitam reuniões e conferências à distância, certo é que nunca tanto se viajou fisicamente como nas últimas décadas, numa época em que porventura se assistiu em simultâneo também a um aumento exponencial de uma mobilidade virtual sobremaneira potenciada pela evolução dos meios e redes digitais. Se bem que os e-mails e as videoconferências possam, de facto, substituir muitas viagens e reuniões de negócios que noutros tempos requeriam uma presença in loco, e as visitas online de museus e outros ex libris turísticos espalhados por todo o globo permitam um fácil acesso às curiosidades e maravilhas do mundo, ainda assim, o fluxo de viajantes “reais”, seja por motivos profissionais ou meramente por lazer, continuou a aumentar de forma galopante, até ao seu fim (provisório) imposto por uma crise sanitária a nível mundial que foi causada por um vírus que na era da globalização viaja infinitamente mais rápido que noutros tempos. Mas mesmo que neste momento ainda não se saiba quando e como será retomada a (hiper)mobilidade que existia antes do confinamento decretado um pouco por todo o globo, é inquestionável que a viagem física continuará a exercer um enorme poder de atração sobre as sociedades pós- 
-industrializadas que, na busca de experiências diferentes por via das deslocações transfronteiriças, não se submeterão de livre vontade a uma lógica meramente pragmática e tecnológica que retira ao ato de viajar a sua dimensão fantástica e mítica de que ao longo dos tempos sempre se revestiu.

Como o formulou o escritor e pintor alemão Max Dauthendey (1919: 44s), num ensaio de viagem publicado há um século, em 1919, com o título Himalayafinsternis (A escuridão dos Himalaias), num volume que veio a lume um ano após a sua morte em Java durante o seu périplo oriental, a viagem parece configurar-se, de uma forma ora mais ora menos filosófica, como uma espécie de vício maldito:

Das ist der Fluch und zugleich die Wollust des Reisens, dass es Dir die Orte, die Dir vorher in der Unendlichkeit und in der Unerreichbarkeit lagen, endlich und erreichbar macht. Diese Endlichkeit und Erreichbarkeit aber zieht Dir geistige Grenzen, die Du niemehr loswerden wirst. Wenn sich Deine Seele, ohne dass Dein Leib reist, an einen Ort hin versetzt, in dem Du nie warst, so kann sie an dem Ort (...) geisterleicht (wandern). Hast Du aber den Ort einmal reisend mit Deinem Leib erreicht und wirkliche Tage dort erlebt, so bist Du dem Gefängnis der Wirklichkeit verfallen. (...) Dies ist der Fluch, der die Seele des Reisenden belastet. Die Flügel der Geistigkeit werden ihm von der Wirklichkeit beschnitten. (Dauthendey 1919: 44s)

[É esta a maldição e, ao mesmo tempo, a volúpia da viagem, o facto de ela te tornar os lugares que anteriormente se encontravam na infinidade e na inalcançabilidade finitos e alcançáveis. Essa finitude e alcançabilidade impõe-te porém limites espirituais dos quais jamais te libertarás. Quando a tua alma, sem que o teu corpo viaje, se transpõe para um lugar onde nunca antes estiveras, ela poderá aí movimentar-se com grande leveza espiritual. No entanto, uma vez que tenhas, viajando, alcançado o lugar com o teu corpo e aí realmente vivido alguns dias, nesse caso ficarás à mercê da prisão da realidade. (...) É esta a maldição que pesa sobre a alma do viajante. As asas da espiritualidade são-lhe cortadas pela realidade.]

Numa época de imobilidade imposta, em que grande parte da humanidade deveria ter a possibilidade de não ter que se deslocar para trabalhar, sendo-lhe no entanto negado o direito ao confinamento, e outra parte, essa bem menor, anseia por poder viajar (em lazer), a reflexão de Dauthendey poderá servir como um consolo, mas duvido que a longo prazo consigamos resistir ao feitiço da viagem física e mental. 


\section{Notas}

* Mário Matos (*1963) é licenciado em Línguas Literaturas Modernas - Francês e Alemão pela Universidade do Porto, Mestre em Literatura e Cultura Alemãs pela Universidade Nova de Lisboa e obteve o seu doutoramento em Ciências da Cultura pela Universidade do Minho, onde é professor do Departamento de Estudos Germanísticos e Eslavos, no Instituto de Letras e Ciências Humanas. As suas principais investigações são na área dos Estudos Culturais e da literatura de viagens. É investigador no Centro de Estudos Humanísticos da Universidade do Minho, onde coordena um grupo de pesquisa de Estudos Transculturais (http://cehum.ilch.uminho.pt/netcult), e é colaborador do Instituto de Literatura Comparada Margarida Losa (U. Porto).

'Optou-se aqui por traduzir apenas as citações do alemão por se tratar de uma língua menos acessível a parte dos leitores. Estas traduções são da minha autoria.

${ }^{2}$ Não se tratando de um relato de viagem propriamente dito, as viagens aos mais diversos lugares do globo atravessam toda a narrativa em que o protagonista se desloca de avião entre Nova lorque e vários países da América Central e do Sul, desde o México, passando pela Venezuela até Cuba, mas também numa travessia transatlântica dos Estados Unidos até Le Havre. Já na Europa, faz uma viagem privada de comboio e automóvel de Paris, passando pelo sul de França, até à Grécia, para além de constantes deslocações em serviço entre Zurique e Berlim.

${ }^{3}$ Nesta e na seguinte citação, os destaques em itálico constam assim do original.

${ }^{4}$ Sobre o "extenso cadastro dos pecados" atribuídos aos turistas na literatura vejam-se, por exemplo, Buzard (2 1998), Hennig (1997: 13-19), Urbain (22002: 33 SS), Culler (198I: I28-131).

\section{Bibliografia}

Anónimo (Archenholz) (1784), “An den Hrn. Herausgeber des T. M. Ueber das Reisen, und jemand der nach Anticyra reisen sollte“. In Der Teutsche Merkur 1784 (4. Vierteljahr), pp. 15I-160.

Augé, Marc (1997), L’Impossible Voyage. Le tourisme et ses images, Paris, Payot \& Rivages.

Berg, Sybille (2016), Wunderbare Jahre. Als wir noch die Welt bereisten, München, Carl Hanser Verlag.

Borges, Jorge Luis (1998), “O Aleph“. In Obras Completas 1923-1949. Vol. I. Lisboa, Teorema, pp. 638-649.

Buzard, James ( $\left.{ }^{2} 1998\right)$, The Beaten Track. European Tourism, Literature, and the Ways to Culture, 1800-1918. Oxford, Clarendon Press. 
Culler, Jonathan (1981), “Semiotics of Tourism”. In American Journal of Semiotics, Vol. I, No. I-2 (1981), pp. 127-140.

Dauthendey, Max (1919), „Himalayafinsternis“. In Die schönsten Geschichten von Max Dauthendey. München, Albert Langen/Georg Müller, pp. 44-66. [Ed. orig.: 1915, in Geschichten aus den vier Winden].

Frisch, Max (1977), Homo faber. Ein Bericht, Frankfurt am Main, Suhrkamp. ['1957]

Frow, John (1991), “Tourism and the Semiotics of Nostalgia”. October, Vol. 57, (Summer, 1991), pp. 123-151.

Goethe, Johann Wolfgang von (1970), Werke: Faust I und II. Wahlverwandtschaften, Band 3, Frankfurt am Main und Leipzig, Insel Verlag.

Hennig, Christoph (1997), Reiselust. Touristen, Tourismus und Urlaubskultur. Frankfurt am Main, Leipzig, Insel Verlag.

Herder, Johann Gottfried (197I), Briefe zur Beförderung der Humanität. Hg. von Hans-Joachim Kruse, Berlin und Weimar.

Huxley, Aldous (21948), Along the Road. Notes and Essays of a Tourist, London, Chatto \& Windus.

Matos, Mário (2010a), Postigos para o Mundo. Cultura Turística e Livros de Viagens na República Democrática Alemã (1949-1989/90), V. N. Famalicão, Húmus.

-- (20।ob) "Os «cruzeiros atlânticos» da organização nacional-socialista Kraft durch Freude (1935-1939) como encenação político-cultural da amizade luso-alemã”, in Maria Manuela Gouveia Delille (coord.), Portugal-Alemanha: Memórias e Imaginários, vol. II, Coimbra: Minerva, pp. 255-283.

Moura, Jean-Marc (2000), “Mémoire culturelle et voyage touristique. Réflexions sur les figurations littéraires du yoyageur et du touriste.” In Maria Alzir Seixo (ed.), Travel Writng and Cultural Memory/Écriture du voyage et mémoire culturelle. Amsterdam, Atlanta, Rodopi, 265-280.

Nebel, Gerhard (1950), Unter Partisanen und Kreuzfahrern. Stuttgart.

Schmidt, Aurel (1998), Von Raum zu Raum. Versuch über das Reisen. Berlin, Merve.

Schütze, Jochen K. (1995), Gefährliche Geographie, Wien, Passagen Verlag.

Stendhal (1973), Voyages en Italie. Paris, Éditions Gallimard.

Urbain, Jean-Didier (2002), L'idiot du voyage. Histoires de touristes. Paris, Editions Payot.

Virilio, Paul (2000), A Velocidade de Libertação. Lisboa, Relógio D’Água. [Tradução e prefácio de Edmundo Cordeiro; 11995] 